\title{
Research of Mining STATCOM Based on Hybrid Multilevel H-bridge Inverter*
}

\author{
Yaopu Li, Cong Wang, Xu Zhao, Kai Zhang \\ China University of Mining \& Technology (Beijing), Beijing, China \\ Email: li.yaopu@hotmail.com
}

Received January, 2013

\begin{abstract}
The paper presents a new STATCOM system based on H-bridge inverter. It can be used in mine power network. It has been commonly verified for the positive effects of SVG on the reactive power compensation and voltage fluctuation suppression. This paper focuses on a generalized structure of multilevel power converter where individual voltage sources are not necessarily the same. The cascade H-bridge consists of two cells, high-voltage cell and low-voltage cell. The high-voltage cell is responsible for voltage lifting, while the low-voltage cell is responsible for PWM modulation. If two cells are cascaded with DC voltages in a ratio of 2:1, the single-phase output voltage can reach 7 levels. Increasing voltage levels of output waveform can bring up AC current quality, optimize harmonic spectrum and enhance converter efficiency. The hybrid multilevel is characterized by per-phase series connection of a high-voltage H-bridge converter and a low-voltage H-bridge converter. Due to the different capacitor voltage, it is a key problem as to how to maintain the capacitor's voltage at a reference level. Independent DC source can effectively ensure the DC voltage. Through the reactive power compensation technology, the three-phase voltage and current can remain at the same phase.
\end{abstract}

Keywords: H-bridge; STATCOM; SVG; Hybrid; Coal Mine; PWM Control; Inverter

\section{Introduction}

Early reactive power compensation is mainly for passive device, which is using a certain capacity of the capacitor or reactor. It is directly connected in parallel or series in a circuit. This kind of device is operated by mechanical switch cut. So the application is mainly used for mechanical cast cut capacitor (MSC). But it has no rapidity, continuity, repeatability characteristics. However, when the SVG come to the application, it can continuous control the impedance of the device and adjust for inductor or capacitor.

With the rapid development of modern coal mine, the use of high power motor brings up a lot of reactive power. This kind of situation is very outstanding in the mining coal face. It becomes obvious especially on-peak demand. Therefore, the dynamic reactive power compensation technology research is of important significance in coal mine underground. It is ensuring the production, saving energy and reducing consumption.

Multilevel power conversion has drawn heavy attention in the area of medium-voltage industrial applications

"The Fundamental Research Funds for the Central Universities. (2010YJ03) Supported by: National Natural Science Foundation of China. (51077125). and high-power applications [1-3]. In [3], the high-voltage H-bridge used IGCT instead of IGBT. It has been proven that the voltage blocking capability of faster devices, such as IGBT, and the switching speed of high voltage thyristor-based devices, such as IGCT, is limited. So the combination of the two types of thyristors can bring each own advantages to the circuit.

When the DC voltages have various ratios, the number of output levels is also different. An extension of conventional multilevel topology with the series connection of unequal DC voltage sources is adopted in literature [4] [5]. The topology effectively output a higher voltage levels compared with traditional H-bridge converter. Literature [5] provides a motor drive direct torque control (DTC) scheme for electric vehicles (EVs) or hybrid EVs. The limitation is that the control method is not applicable to STATCOM in which capacitors are replaced in dependent DC power.

Compared with conventional STATCOM, some paper proposed a new topology from hybrid cascading one NPC inverter and several conventional H-Bridge inverters. A control method is also proposed to realize DC voltage regulation of series-connected multiple cells in the STATCOM operation, making it possible to remove DC sources from all H-bridge cells [6]. It will eliminate 
the cumbersome transformers and meanwhile all the advantages of $\mathrm{H}$-Bridge cascade inverter can be kept. But when the number of cascade H-bridge increases, the control method will also become more complex[7,8]. In order to keep the balance of DC voltages, many DC sources are consist of isolate power supplies [9], independently powering each cell.

The aim of this paper is to clarify the advantages of the 7-level output voltage. Y-type cascaded Hybrid single-phase H-bridge topology was used for its modularity and simplicity. A hybrid frequency carrier-based PWM control strategy is presented in this paper. Every cluster is comprised of a 7-level hybrid inverter, high-voltage $\mathrm{H}$-bridge converter and low-voltage $\mathrm{H}$-bridge converter. The DC bus voltages were configured in the ratio of $2: 1$. And they also work in unequal switching frequency.

\section{Configuration of the STATCOM System}

Figure 1 shows the principle of parallel SVG configuration. For application in coal mine, the majority of the load is inductive. So the SVG should compensate the inductive reactive.

Figure 2 shows current vector of the Figure 1. Where Us is the grid side voltage; Is the grid side current; $U_{L}$ is the voltage drop in the inductance; $\mathrm{U}_{\mathrm{I}}$ is the output voltage of three-phase inverter bridge. We can measure the magnitude of the power line voltage Us and current Is, as well as their phase $\alpha, \beta$. In the ideal case, the connecting reactor is regarded as inductance. We do not consider the various losses. Inductance on the direction of the current lags the voltage of 900 . So Us and $U_{I}$ are maintained in the same phase. The magnitude and direction of the voltage drop in the inductance can be controlled by changing the amplitude of the $\mathrm{U}_{\mathrm{I}}$, whereby the magnitude and direction of the current in the inductance be controlled. According to Kirchhoff's voltage law, $U_{I}$
$=\mathrm{Us}-\mathrm{U}_{\mathrm{L}}$. Inductive reactive power that SVG absorbed from the grid is equivalent to the capacitive reactive power output to grid. As a result, we need to keep the reactive current ILref equal to the reactive current of the load. This is called direct current control theory.

Figure 3 illustrates the three-phase cascaded H-bridge circuit used in this paper. For cascade H-bridge inverter, there are two main topology connections, Delta-type and Y-type. In this paper, we use Y-type cascade topology.

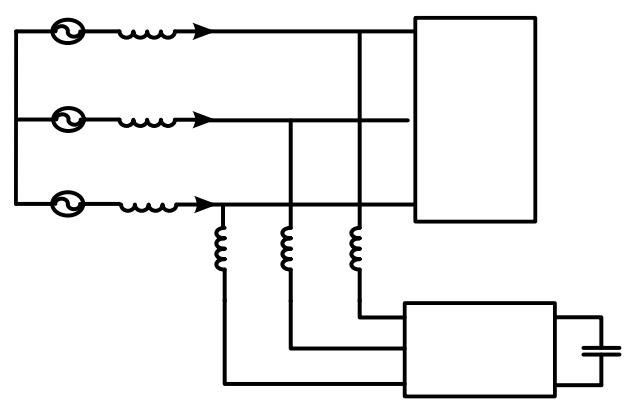

Figure 1. Downscale of Reactive power compensation system.

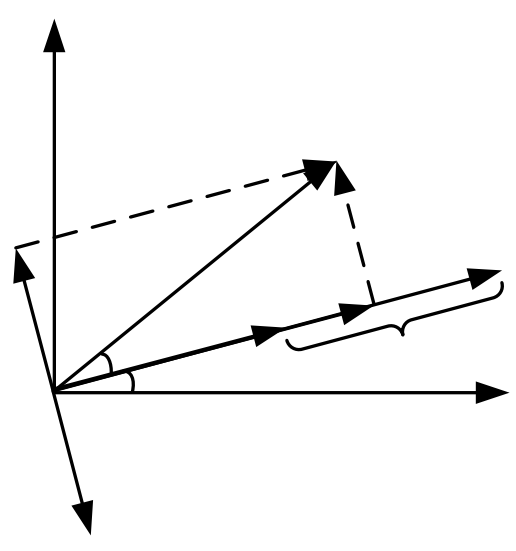

Figure 2. The current vector.

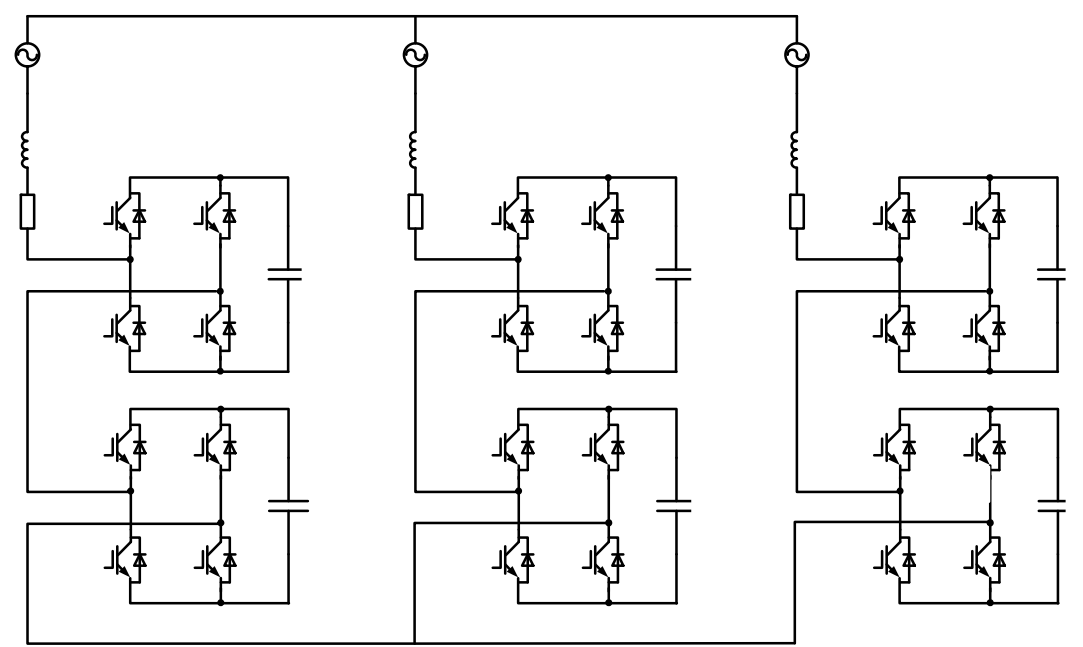

Figure 3. Y-type connection of SVG inverter topology. 


\section{Control Strategy of SVG}

\subsection{Modulation Strategy of SVG Converter}

The three-phase inverter is composed of three Clusters. Each cluster of the hybrid multilevel inverter combines a high-voltage converter cell 1 with 200 V DC-link, and a low-voltage converter cell 2 with 100 V DC-link. Switching frequencies of $50 \mathrm{~Hz}$ and $1 \mathrm{kHz}$ are assigned to highvoltage converter and low-voltage converter in this experiment.

The high-voltage bridge arm is responsible for voltage lifting, while the low-voltage bridge arm is responsible for PWM rectifier. Seven-level output voltages are -300 , $-200,-100,0,100,200$ and 300, respectively shown in Figures $\mathbf{4}$ and 5. For example, when the desired output is between 0 and 100, the high-voltage bridge should output 0 and the low-voltage bridge output 0 to 100 . When the desired output is between 100 and 200, the high-voltage bridge should output 200 whereas the low-voltage bridge output 0 to -100 . Through this PWM control strategy, the two-stage voltage stack can output seven levels. Control strategies of each cell are individually shown in Table 1.
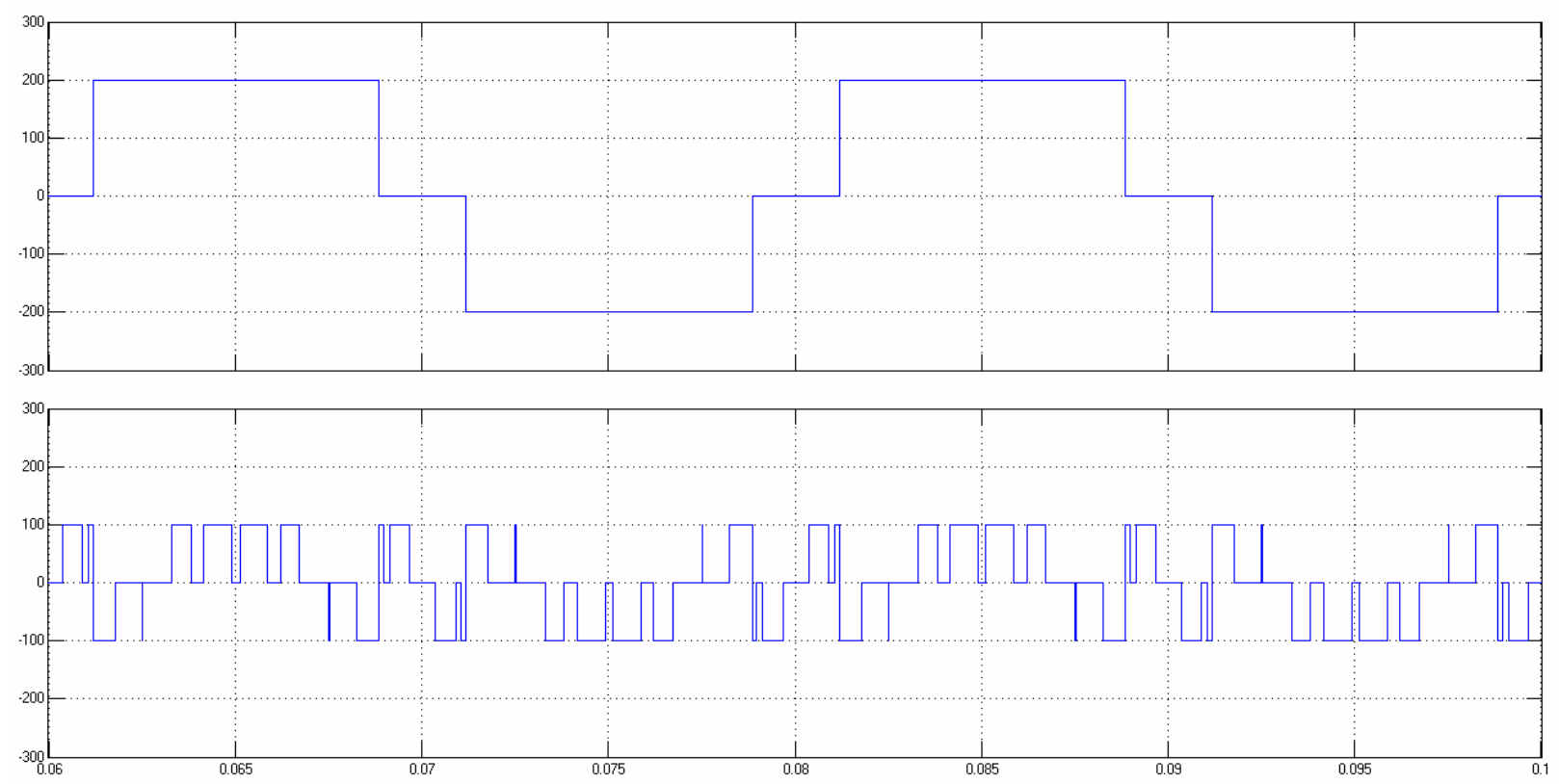

Figure 4. Square waveform of Cell1 and PWM waveform of Cell 2.

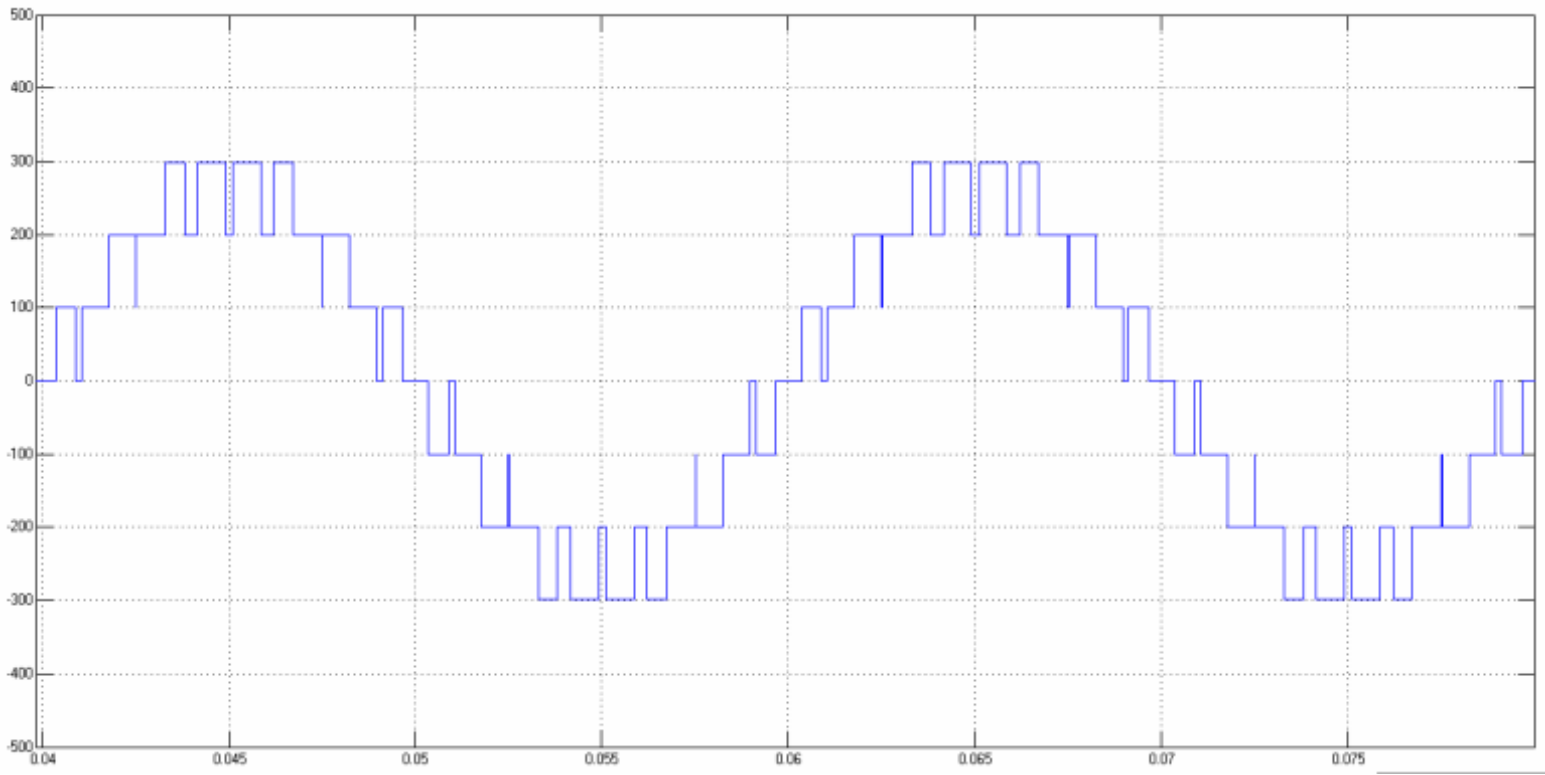

Figure 5. Hybrid sever-level PWM modulation scheme. 


\subsection{Instantaneous Reactive Power Detection}

Assume that $e_{a}, \mathrm{e}_{\mathrm{b}}, e_{c}$ and $i_{a}, i_{b}, i_{c}$ are the three-phase voltage and current values of the circuit. To facilitate analysis, the voltage current instantaneous value of the three-phase static coordinate system $a-b-c$ can be transformed into two-phase static coordinate system a $\beta$.This is called Clarke transformation.

$$
\begin{aligned}
& {\left[\begin{array}{l}
e_{\alpha} \\
e_{\beta}
\end{array}\right]=C_{32}\left[\begin{array}{l}
e_{a} \\
e_{b} \\
e_{c}
\end{array}\right]=\sqrt{\frac{2}{3}}\left[\begin{array}{ccc}
1 & -\frac{1}{2} & -\frac{1}{2} \\
0 & \frac{\sqrt{3}}{2} & -\frac{\sqrt{3}}{2}
\end{array}\right]\left[\begin{array}{l}
e_{a} \\
e_{b} \\
e_{c}
\end{array}\right]} \\
& {\left[\begin{array}{l}
i_{\alpha} \\
i_{\beta}
\end{array}\right]=C_{32}\left[\begin{array}{l}
i_{a} \\
i_{b} \\
i_{c}
\end{array}\right]=\sqrt{\frac{2}{3}}\left[\begin{array}{ccc}
1 & -\frac{1}{2} & -\frac{1}{2} \\
0 & \frac{\sqrt{3}}{2} & -\frac{\sqrt{3}}{2}
\end{array}\right]\left[\begin{array}{l}
i_{a} \\
i_{b} \\
i_{c}
\end{array}\right]}
\end{aligned}
$$

The instantaneous active current and instantaneous reactive current of the system can be calculated through Park transformation. This current is expressed as:

$$
\begin{aligned}
{\left[\begin{array}{c}
i_{p} \\
i_{q}
\end{array}\right] } & =C_{22}\left[\begin{array}{l}
i_{\alpha} \\
i_{\beta}
\end{array}\right]=\left[\begin{array}{ll}
\frac{e_{\alpha}}{e} & \frac{e_{\alpha}}{e} \\
\frac{e_{\alpha}}{e} & \frac{e_{\alpha}}{e}
\end{array}\right]\left[\begin{array}{l}
i_{\alpha} \\
i_{\beta}
\end{array}\right] \\
& =\left[\begin{array}{cc}
\sin \omega_{1} t & -\cos \omega_{1} t \\
-\cos \omega_{1} t & -\sin \omega_{1} t
\end{array}\right]\left[\begin{array}{l}
i_{\alpha} \\
i_{\beta}
\end{array}\right]
\end{aligned}
$$

As is shown in Figure 6, the three-phase grid voltage and current are assumed as $\mathrm{U}_{\mathrm{a}}, \mathrm{U}_{\mathrm{b}}, \mathrm{U}_{\mathrm{c}}$ and $\mathrm{I}_{\mathrm{a}}, \mathrm{I}_{\mathrm{b}}$ and $\mathrm{I}_{\mathrm{c}}$. $\mathrm{I}_{\mathrm{al}}$, $\mathrm{I}_{\mathrm{bl}}$ and $\mathrm{I}_{\mathrm{cl}}$ are the three-phase current of the inductance. After 3-2 Clarke and Park transformation of current, we can get the inductance reactive current $\mathrm{I}_{\mathrm{q} 1}$ and grid reactive current $I_{\mathrm{q}}$. Compare the reactive current of the inductance with the reactive current of the grid, then put the subtraction $\mathrm{Id}^{*}$ into PI regulator. In this way, the reactive current of the grid can be tracked and compensated. The circuit is regarded as an ideal model that does not deliver active power to the grid. The output of the PI regulator is the three-phase input voltage of the cascade inverter, which are $\mathrm{U}_{\text {aref }}, \mathrm{U}_{\text {bref }}$ and $\mathrm{U}_{\text {creff }}$.

\section{Simulation of the Hybrid Multilevel H-bridge STATCOM}

In order to validate the proposed hybrid cascaded inverter structure and the control algorithm, a hybrid seven level cascade inverter simulation has been built in Simulink.

Figure 7 illustrates the phase difference between the

Table 1. Control stategy.

\begin{tabular}{ccc}
\hline $\begin{array}{c}\text { Desired output } \\
\text { voltage }\end{array}$ & $\begin{array}{c}\text { High-voltege } \\
\text { converter }\end{array}$ & $\begin{array}{c}\text { Low-voltage } \\
\text { converter }\end{array}$ \\
\hline $0 \rightarrow 100$ & 0 & $0 \rightarrow 100$ \\
$100 \rightarrow 200$ & 200 & $0 \rightarrow-100$ \\
$200 \rightarrow 300$ & 200 & $0 \rightarrow 100$ \\
$0 \rightarrow-100$ & 0 & $0 \rightarrow-100$ \\
$-100 \rightarrow-200$ & -200 & $0 \rightarrow 100$ \\
$-200 \rightarrow-300$ & -200 & $0 \rightarrow-100$ \\
\hline
\end{tabular}

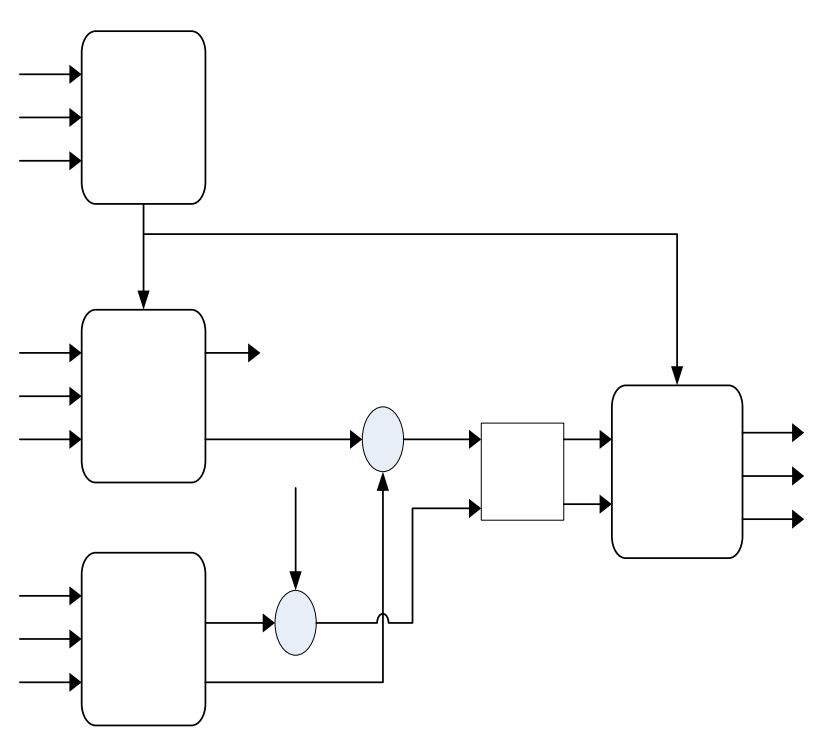

Figure 6. The strategy of reactive power detection.

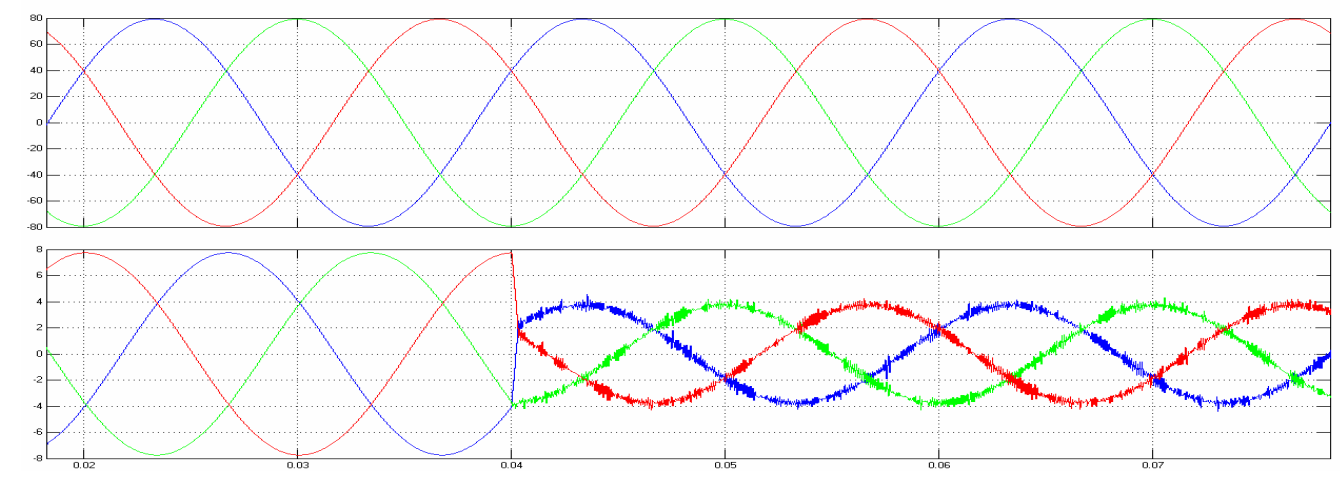

Figure 7. Phase comparison of voltage and current after compensation. 

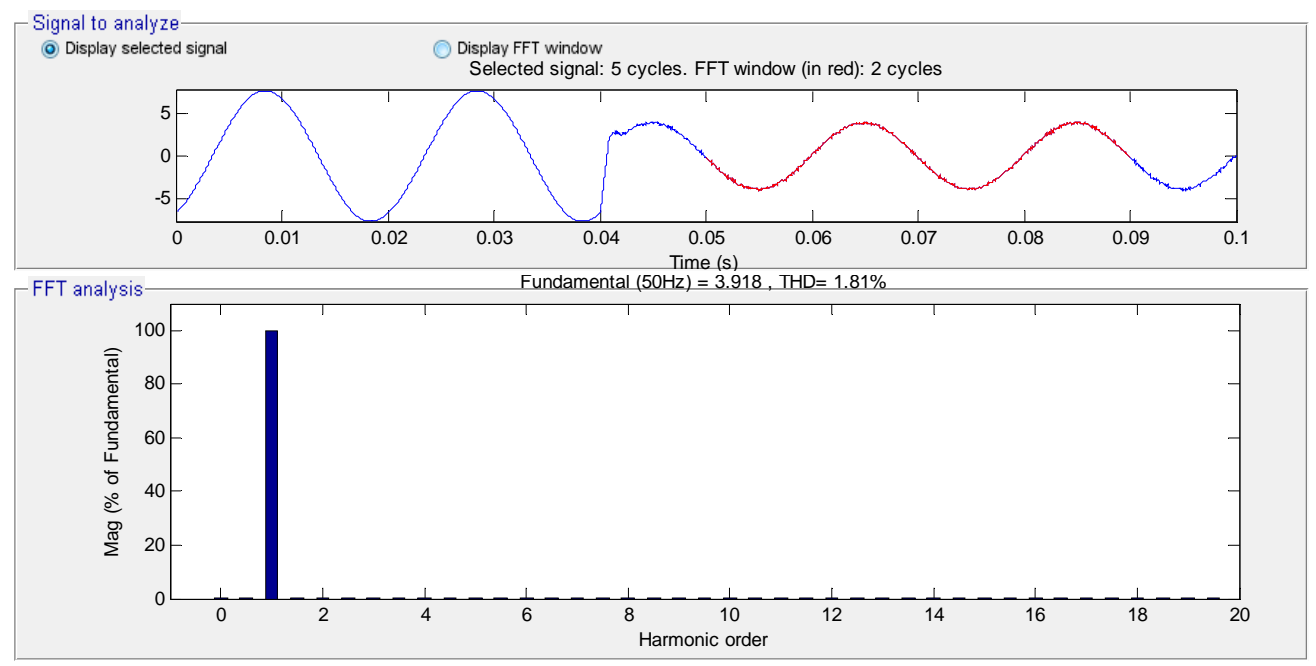

Figure 8. FFT analysis of compensation current IL.
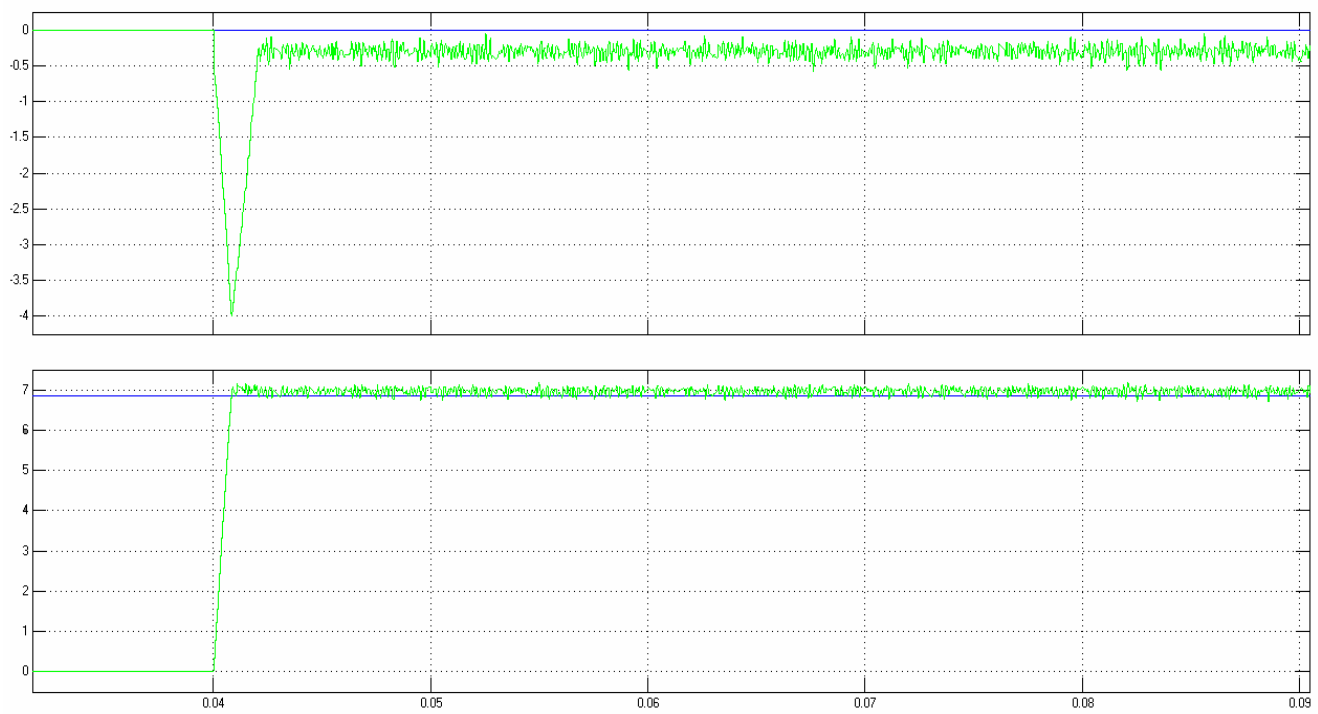

Figure 9. The tracking waveform of active and reactive current.

voltage and cureent of the three-phase grid after the compensasion when $t=0.04 \mathrm{~s}$. Before compensation, as the connecting reactor is regarded as inductance in the ideal case, the voltage phase is therefore ahead of the current phase by $90^{\circ}$. When the reactive power compensation is integrated in the system, the two waveforms maintain in the same phase.

Figure 8 shows the FFT analysis of the compensation current. The THD $=1.81 \%$ with a better harmonic spectrum.

Tracking situation of the active and reactive current is shown as in Figure 9.

\section{Conclusions}

Based on the input DC-level of hybrid cascaded multi- level transform circuit, this paper proposed a new PWM control method. The two cascaded H-bridge have different DC voltages. The Matlab simulation results have shown that by stacking the output current, the proposed operation strategy is feasible. It effectively improves the system output voltage level and simultaneously reduces the harmonic content.

Due to the fact that cascade control of multilevel inverter is based on individual phase control, it is faster to offset current reaction speed by direct current control of the converter.

This paper studies a kind of applied DC power hybrid cascade STATCOM. With the right control strategy to directly control the voltage of the capacitance, cost will be lower and operation more practical. This will greatly promote the application of reactive power compensation. 


\section{REFERENCES}

[1] M. D. Manjrekar and T. A. LipoA, "Hybrid Multilevel Inverter Topology for Drive Applications," Conference Proceedings - IEEE Applied Power Electronics Conference and Exposition - APEC, Vol. 2, 1998, pp. 523-529.

[2] M. D. Manjrekar, Peter-steimer and T. A. Lipo, "Hybrid Multilevel Power Conversion System: a competitive solution for high power applications," Conference Record of the 1999 IEEE Industry Applications Conference. Thirty-Forth IAS Annual Meeting (Cat. No.99CH36370), Vol. 3, 1999, pp. 1520-1527.

[3] M. Veenstra and A. Rufer, "Control of a Hybrid Asymmetric Multilevel Inverter for Competitive Medium-Voltage Industrial Drives," IEEE Transactions on Industry Applications, Vol. 41, No. 2, 2005, pp. 655-664. doi:10.1109/TIA.2005.844382

[4] M. D. Manjrekar and T. A. Lip0A, "Generalized Structure of Multilevel Power Converter," 1998 International Conference on Power Electronics Drives and Energy Systems for Industrial Growth (IEEE Cat. No.98TH8362), Vol. 1, 1998, pp. 62-67.

[5] F. Khoucha, S. M. Lagoun, K. Marouani, A. Kheloui and M. E. H. Benbouzid, "Hybrid Cascaded H-Bridge Multi-
level-Inverter Induction-Motor-Drive Direct Torque Control for Automotive Applications," IEEE Transactions on Industrial Electronics, Vol. 57, No. 3, 2010, pp. 892-899. doi:10.1109/TIE.2009.2037105

[6] K. Sano and M. Takasaki, "A Transformerless D-STATCOM Based on a Multi-Voltage Cascade Converter Requiring No DC Sources," 2011 IEEE Energy Conversion Congress and Exposition (ECCE 2011), pp. 3151-3158, 2011.

[7] Y. Xu, Y. P. Zou, W. Chen, C. Z. Wang, X. Liu and F. Li, "A Novel STATCOM Based on Hybrid Cascade Multilevel Inverter," 2008 IEEE International Conference on Industrial Technology (ICIT), 2008, p. 6.

[8] Tolbert, L.M., Chiasson, J.N., McKenzie, K.J., Zhong Du, "Control of Cascaded Multilevel Converters with Unequal Voltage Sources for HEVs," IEMDC'03. IEEE International Electric Machines and Drives Conference (Cat. No.03EX679): 078037817 2, p 663-9 vol.2, 2003.

[9] A. Rufer, M. Veenstra and K. Gopakumar, “Asymmetric Multilevel Converter for High Resolution Voltage Phasor Generation," Proc. of European Conference on Power Electronics and Application (EPE), 1999. 